\title{
A geografia mítica do boi
}

\author{
Amarildo Menezes Gonzaga*
}

Resumo: O ensaio busca compreender o boi enquanto ser mítico que habita o imaginário de diversas civilizações antigas. A relação homem/boi é revista através do itinerário que vai da sacralização do animal até sua atual configuração, passando pela fase que inspira o terror. Medo e adoração estariam nas raízes do folguedo boi-bumbá, uma forma de divinização contemporânea.

Palavras-chave: boi-bumbá, mitologia clássica, imaginário, deuses animais.

Abstract: The essay aims to understand "boi" as a mytical being that lives into imaginary of several old civilizations. The connection human being/boi is seen through the specific way from as it is as animal sacredness to its present position, until terror inspiration. Basicaly, fear and adoration would be into "boi-bumbá" roots, which means a comtemporary divinity way.

Keywords: boi-bumbá, classical mitology, imaginary and animal gods.

\section{Introdução}

uem assiste ao Festival Folclórico de Parintins ou dele com interesse
ouve falar, provavelmente não imagina que o amor (ou o ódio) por um
dos bumbás envolvidos na disputa possui um componente mitológico: a
adoração (e o temor), desde os tempos primeiros da humanidade sobre a
Terra, a deuses animais ou a entes superiores com partes do corpo "anima-
lizadas”. No caso específico da festa parintinense, o remanescente mítico se
relaciona à figura do boi. Dizer isso, porém, não constitui novidade, haja
vista que os mais variados aspectos de nossa civilização têm suas raízes no

* Mestre em Natureza e Cultura na Amazônia e professor de Literatura do ensino médio. 
mito. Citemos, a propósito, o Carnaval, oriundo das comemorações com que, na Antigüidade Clássica, se homenageavam Baco, Saturno e Pã - este, um ser híbrido, metade humano, metade bode.

Construímos a mencionada geografia - a que denominamos de mítica procurando entender o boi como centro de um universo eminentemente religioso, que reflete um modelo de estrutura social resultante de uma mentalidade dita como primitiva. Para consubstanciar essa parte do trabalho, fizemos uma abordagem descritiva a respeito da relação estabelecida entre diferentes civilizações antigas com aquele animal. Nesse itinerário foram consideradas inúmeras praticas ritualísticas desenvolvidas por diferentes povos, utilizando o objeto em enfoque como um recurso capaz de dar sentido às suas vidas, em uma época em que era fértil a crença em todo e qualquer mecanismo que pudesse servir de evidência para explicar o sobrenatural. No mais, há ainda a presença de fatos e narrativas que envolvem histórias experimentadas por vários povos. Todas essas situações voltadas para consubstanciar o que nos propusemos, ou seja, entender a relação estabelecida entre o homem e um importante animal: o boi.

\section{Iniciamos a trajetória...}

Considerando que os animais sempre fizeram parte da vida do homem, assim como das diferentes situações que ele utilizou para construir sua civilização. Em uma retrospectiva na história da humanidade, é possível constatar que muitos deles sempre foram cultuados por vários povos em diferentes lugares do mundo, sendo que alguns até chegaram a adquirir personificação, ganhando a condição de personagem principal em mitos criados para justificar a fé, o modo de ser e de viver. Ademais, baseamo-nos, a fim de justificar a interpretação que atribuímos ao vocábulo mito, em Orlando Pires, que, a partir de Mircea Eliade, afirma, no Manual de teoria e técnica literária, o seguinte:

O mito é uma realidade cultural extremamente complexa que pode ser abordada e interpretada de múltiplas perspectivas. Constitui sempre a narrativa de uma criação: relata de que modo alguma coisa foi produzida e começou a existir. Limita-se a registrar o que realmente aconteceu, o que chegou a manifestar-se plenamente (Pires, 1985, p. 283).

Se forem averiguados os estudos desenvolvidos por paleontólogos sobre a história da humanidade, poderá ser detectado o estabelecimento da relação homem/animal através de diferentes figuras de animais pintados nas pare- 
des das cavernas habitadas pelos primitivos há muitos anos. Como se pode interpretar essa relação? Como busca de realização constante? Como satisfação existencial? Ou como modo de interpretar os mistérios que cercavam o cotidiano primitivo, capaz de expressar a vida muitas vezes partindo de um conjunto de símbolos criados exclusivamente com essa finalidade?

Todas estas e outras situações fazem parte dos fios que alinhavam a indumentária mítica que veste o imaginário do homem desde os tempos primordiais. As mudanças que nela se observam são conseqüência da incessante busca existencial por que o próprio homem passa, com o intuito de uma possível realização pessoal completa. Os canais mediadores que conduzem o homem são a imaginação e a realidade. Dentre os elementos que estruturam os fios míticos, estão inúmeros conjuntos de símbolos, como é o caso de uma variedade de animais, inclusive o boi.

Apesar de fazer parte do cotidiano do homem em diversas civilizações, o boi acabou remotamente sendo transposto para o seu imaginário, assumindo a condição de um deus. Além de divindade era, ao mesmo tempo, alimento que necessitava ser constantemente introjetado nas veias da fantasia, nos momentos de desprendimento daquilo que a rústica realidade da vida impunha. Sendo assim, o boi era o recurso mediador advindo do imaginário humano para neutralizar relações conflituosas estabelecidas com o seu cotidiano.

Se contextualizarmos o boi em diferentes culturas, poderemos constatar que ele é um símbolo de bondade, de calma, de força pacífica, de capacidade de trabalho, de sacrifício. Além disso, em determinados momentos, observamos que, com o mesmo sentido mítico, também há referências ao touro em diferentes civilizações antigas. Portanto, iremos, da mesma forma, falar sobre o touro, que pertence a igual campo semântico, em diferentes sociedades.

Sobre a trajetória histórica do boi (e similares) entre a humanidade, encontramos informações de sua existência, na condição em que a estamos enfocando, já a partir do período paleolítico. Pelo menos é o que nos informa Elizabeth Loibl, na obra Deuses animais:

O auroque ou boi selvagem (Bos primigenius), extinto em 1627, é encontrado, sob diferentes subespécies, em vastas regiões da Terra. Era, para o homem paleolítico, de relevante importância. $O$ touro parece ter exercido estranho domínio sobre os povos da Terra. A veneração por esse animal estendeu-se por largas regióes: Africa setentrional (cavernas neolíticas mostram desenhos de touro com o sol entre os cornos); a antiqüíssima cultura badari, no Egito (por volta de 4000 a.C.); Palestina (o bezerro de ouro 
de Aarão); no Templo de Salomão, uma bacia carregada por doze touros. (...) Na Mesopotâmia, foram encontradas cerâmicas pertencentes à cultura Tell Halaf (4000 a.C.), com representações estilizadas: bois ou cabeças de bois (Loibl, 1992, p. 22).

Apesar das diversidades religiosas na Antigüidade, tem razão Elizabeth Loibl quando afirma que "povos das mais diferentes raças e culturas, que provavelmente jamais tiveram contato entre si, possuíam, no entanto, um ponto em comum: a veneração ao animal”. Os motivos dessa identificação não são objetivo deste trabalho, bastando-nos constatar que "este culto deixou marcas profundas no ser humano, em todos os tempos” (Idem, p. 16). Quer-nos parecer, porém, que o culto primitivo a tais divindades sempre conduzia a um princípio: levar o homem a buscar respostas às mais diversas situações relacionadas à vida cotidiana. Ainda que não tivesse se descoberto como sujeito de sua própria história, procurava estabelecer relações com as coisas e os animais que faziam parte da realidade, relacionando-os da maneira mais convincente possível com o seu imaginário. Assim conduzia a vida na crença de que, através de manifestações míticas, poderia dar significado sobrenatural a vida de seres que o resguardariam das inúmeras incertezas e medos que até então apresentavam-se inexplicáveis no ingênuo e fértil universo de entendimento da vida.

Por julgarmos necessário, citemos, ainda do livro de Elizabeth Loibl, outras referências a formas de veneração ao touro:

Também os achados dos grandes impérios assírios de Uruk, Djemdet Nasr, Mesilim, Lagash e Akkad (3000 a 2000 a.C.), tinham inúmeros ornamentos de touros, tanto selvagens como domesticados. O palácio do rei assírio Sargão II era enfeitado com touros dotados de asas e cabeças humanas. Sabe-se que as culturas do vale Indo, no Paquistão, conheciam o touro. No Beluchistão os arqueólogos encontraram vasos de argila com desenhos de bois e zebus, bem como pequenas esculturas desses animais, datadas de até 3000 a.C. (...). Provavelmente a milenar veneração da vaca na Índia tem suas raízes nessas velhas culturas do Indo. Segundo a lenda, Xiva está montado no touro Nandi, ainda hoje freqüentemente encontrado diante de muitos templos, como enorme escultura (Idem, p. 22-3).

Outros bois ou touros também podem ser destacados na condição de sagrados em universos distintos dos que foram mencionados até agora. É o caso de Ápis, no Egito, e de Buchis, em Tebas. E temos, apenas para citarmos mais um exemplo, Mnevis, cujo nome 
era a princípio Merur, porém os gregos o transformaram em Mnevis. Foi venerado em Heliópolis, a cidade do deus-sol Rê-Atum. Como Mnevis era a personificação do deus-sol, o faraó monoteísta Iknáton transferiu seu culto para Amarna, ou seja, Aketaton, cidade-sol, cidade-sonho, primeiro gigantesco projeto urbano da história da humanidade. Mnevis era um touro negro, sem qualquer sinal. Mas devia ter tufos de pêlo no corpo, bem como na cauda, com indicativos de sua divindade. Viveu em meio a um rebanho de vacas e bezerros sagrados, não tão venerados como ele, mas que tinham direito a um sepultamento honroso (Idem, p. 45-6).

O Dicionário de Símbolos, de Jean Chevalier e Alain Gheerbrant, no verbete "Boi, Búfalo”, dá outras informações relevantes, principalmente no que concerne à adoração ao último, ampliando o que vimos desenvolvendo:

O búfalo é mais rústico, mais pesado, mais selvagem. A iconografia hindu faz dele a montaria e o emblema de Yama, divindade da morte. Igualmente, no Tibete o espírito da morte tem cabeça de búfalo. Entretanto, entre os gelupgas - seita dos Barretes amarelos -, o Bodhisattva Manjushri, destruidor da morte, é representado com cabeça de búfalo. (...) Entre as populações montanhesas do Vietnã, para as quais o sacrifício do búfalo é o ato religioso essencial, esse animal é respeitado do mesmo modo que um ser humano. Sua morte, através do rito sacrificial, transforma-o no enviado, no intercessor da comunidade junto aos Espíritos superiores (Chevalier \& Gheerbrant, 1995, p. 137).

Boi, touro, búfalo, vaca. Qualquer um desses animais ganha espaço no universo mítico do homem primitivo (e também, em alguns casos, na mente do homem contemporâneo). Com certeza por possuírem a mesma natureza, ganham espaço significativo no imaginário construído desde as mais remotas épocas. A bravura do touro, que reflete a sua assimilação como um ser potente, serve para nortear o princípio significativo que permeia a relação homem/animal. É uma alternativa de preenchimento da lacuna científica que ainda hoje atinge e acompanha o homem, apesar de todo avanço que tem obtido. Permanecem as questões fundamentais, jamais respondidas, sobre a sua origem e seu destino no universo, etc.

O deus Mnevis, a quem já nos referimos, é um exemplo que pode ilustrar a situação acima, uma vez que foram inseridos motivos divinos em sua condição de touro, em conseqüência de certas similaridades que só ele possuía. A partir disso, evidencia-se a relação vertical que o homem buscava estabelecer com outros seres, como corolário de uma contingência existen- 
cial que funcionava também na condição de alternativa para a efetivação da fuga de incertezas advindas, em que pese a força do cotidiano.

O referencial boi/touro é o centro que serve de elemento de retroalimentação do imaginário humano, a fim de fortalecer e não deixar morrer a simbologia sustentadora de motivos míticos. Dessa maneira, ao cultuar tais divindades, o homem cria uma maneira sobrenatural de descrever coerentemente a realidade. Como se fosse uma maneira mágica de agir, a fim de se tranqüilizar com os inúmeros acontecimentos que o assustavam e o levavam a interpretar o mundo em que vivia.

Muitos outros exemplos poderiam ser dados, mas tal prática apenas tornaria cansativo o trabalho. Cremos ter estabelecido alguns parâmetros relativos à adoração. Cumpre-nos agora ver o lado sombrio, o lado do terror: o touro como inspirador do medo. A esse respeito, nada é mais significativo que o Minotauro, o habitante do famoso labirinto, na Creta do período minóico. Dentre diversas informações relativas a tal ser - mistura de duas espécies -, encontramos, no Dicionário de Mitologia Grega, de Ruth Guimarães, as seguintes:

Dava-se o nome de Minotauro a um monstro que tinha corpo de homem e cabeça de boi. Chamava-se realmente Astério e era filho de Pasífae, a mulher de Minos, e de um touro enviado pelo deus Posídon àquele rei. Horrorizado e cheio de vergonha com o nascimento desse monstro, Minos encarregou o artista ateniense Dédalo de construir um imenso palácio, o Labirinto (...). Ali encerrou o Minotauro, o qual cevava o seu apetite em vítimas humanas (Guimarães, 1993, p. 224).

Imposto ao rei Minos como punição pelo não cumprimento de uma promessa ao deus do mar, o Minotauro simboliza o castigo, uma purgação dos pecados por ofensas perpetradas às divindades. Necessário exterminá-lo, ao invés de adorá-lo. O monstro está em paralelo com o demônio do cristianismo. Eis a função de Teseu, o herói ático que o exterminou. Para tanto, contou com um auxiliar precioso: "Ariadne, uma das filhas de Minos enamorouse perdidamente do belo Teseu. Para que encontrasse o caminho de volta, deu-lhe um novelo de fio, que ele deveria amarrar, na entrada, e ir desenrolando" (Idem, p. 292). Ocorreu, então, a luta entre homem e demônio, entre o homem e as forças inferiores que renega: "Teseu empenhou-se em luta com o Minotauro, matando-o a punhaladas, e saiu do Labirinto levando os companheiros” (Idem, p. 292). 
Uma contrapartida ao boi em seu aspecto negativo - caso específico do Minotauro - encontramos ainda em Creta, durante a civilização minóica. Pois se o homem-touro era filho de Pasífae, a mulher de Minos, com um touro enviado por Netuno, do casal real nasceu Glauco, cujo nome significa "verde mar". Criança normal, sem deformidades, sobre ela se abateu a tragédia de morrer afogada em um barril de mel. No livro Os Deuses Gregos, de Karl Kerényi, encontramos maiores detalhes a respeito dessa narrativa e de sua relação com o maravilhoso que envolve os bois e animais similares:

Ninguém sabia o que fora feito do menino. Consultado, um oráculo respondeu: "Uma criatura maravilhosa nasceu entre vós: quem quer que encontre a verdadeira semelhança dessa criatura encontrará também a criança". Nos rebanhos de Minos nascera um bezerro que mudava de cor três vezes por dia: era primeiro branco, depois vermelho e finalmente preto. Um adivinho de Argos, um homem chamado Políido, "o que sabe muito", encontrou a verdadeira semelhança: a amora silvestre. Pois a amora silvestre também é primeiro branca, depois vermelha e, finalmente, preta (Kerényi, 1994, p. 93).

Graças ao bezerro, em um aspecto inusitado, qual seja, o de intermediário entre deuses e homens, Glauco pôde ser encontrado. $\mathrm{O}$ aspecto mítico a que nos referimos não deve ser desconsiderado, pois foi justamente o que se estabeleceu na literatura: os bichos vistos sob a ótica do maravilhoso. No literário, observamos que os animais perdem a condição de divindade. Elas se encontram, muitas vezes, no mesmo plano que os homens, falam, pensam - oportunidade em que, pela abolição da realidade física, estabelece-se o maravilhoso. Quase sempre, porém, representam o lado sombrio da sociedade e dos indivíduos, um mergulho no inconsciente, a revelação de forças ocultas que preferimos ignorar, em virtude de alterarem profundamente nosso cotidiano e nossas relações. Tal é, sem dúvida, um dos sentidos possíveis de estabelecer para A Metamorfose, de Franz Kafka, novela em que o protagonista Gregor Samsa acorda, certa manhã, transformado em monstruoso inseto.

O mito, porém, por se referir a tempos arcaicos, muito próximos ao caos, em estágios civilizatórios incipientes, concede aos animais a divinização. Comentemos, de maneira específica, a respeito da passagem bíblica do Antigo Testamento, no Livro do Êxodo, que versa sobre o bezerro de ouro. Como se sabe, o povo escolhido, ao verificar que Moisés não descia do monte, impacientou-se e resolveu negar todos os ensinamentos propor- 
cionados por ele. Reuniu-se em torno de Aarão e lhe solicitou que fizesse deuses que caminhassem à frente. Aarão disse:

"Tirai os brincos de vossas mulheres, vossos filhos e vossas filhas, e trazeios a mim”. Todo o povo arrancou os brincos de ouro que usava, e os trouxe para Aarão. Recebendo ouro, ele o moldou com o cinzel e fez um bezerro fundido. Então eles disseram: "Aí tens, Israel, os deuses que te fizeram sair do Egito!’. Ao ver isto, Aarão construiu um altar diante da imagem e proclamou: "Amanhã haverá festa em honra do Senhor”. Levantando-se na manhã seguinte, ofereceram holocaustos e apresentaram sacrifícios pacíficos (Bíblia Sagrada, Ex. 32, 2-6).

Por se ter sentido ameaçado em conseqüência da perda de um referencial divino, logo foi necessário buscar outro que pudesse substituí-lo. Não importava a origem da nova divindade. O imprescindível era cultuá-la a partir de rituais que explicitassem a evidência do que poderia ser perceptível, sem mesmo haver exigência de comprovações do seu valor no imaginário popular.

Além do mais, a dimensão da angústia de cada indivíduo acaba influenciando e levando o coletivo a adaptar-se acriticamente à transgressão das normas da tradição, que antes tinha sido sustentáculo do povo judeu. Tudo porque o bezerro de ouro assumiu momentaneamente a condição de divindade, deixando visível, na seqüência, o comprometimento com uma nova realidade que estava sendo construída nas mentes.

Antes de terminarmos este percurso inicial, uma pergunta se impõe, por fundamental: qual a razão da adoração ao touro, cultuado por diferentes povos da humanidade durante sete mil anos?

Elizabeth Loibl descarta a hipótese da fertilidade, que não se sustenta: "Basta compará-la com a do coelho, do cão, dos ratos e camundongos. A maior fertilidade destes provavelmente também fora notada pelo homem neolítico" (Loibl, 1992, p. 60). E prossegue, acenando com uma possibilidade assaz interessante, apesar de discutível: o touro, tal como a serpente, foi associado a um cometa por muitas civilizações arcaicas:

Cobra ou touro, é uma questão de interpretação. O cometa, por vezes, parece uma enorme cobra incandescente ou um corno. Por vezes, uma enorme massa incandescente, lembrando talvez um touro enfurecido. Isto seria [a] possível explicação de como surgiu o culto do touro entre os povos da Antigüidade. O touro simbolizaria um cometa, como a deusa Ishtar simbolizaria o planeta Vênus, o deus solar, o sol, etc. (Idem, p. 60-61). 


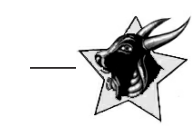

Paradoxalmente, aquele que causa temor é objeto de adoração, fenômeno que se observa na civilização judaico-cristã, sob cuja ideologia vivemos. Devemos "amar a Deus sobre todas as coisas", mas temê-lo, porque seus olhos estão em todo lugar e tudo vêem.

No entanto, uma distinção básica existe entre o culto ao deus cristão e aos deuses animais. Enquanto dá-se ao primeiro um caráter de eternidade, o segundo se sujeita à efemeridade típica dos mortais. Assim, um fenômeno natural, como um cometa-touro, precisa ser enfrentado:

$O$ acontecimento atemorizador personificaria o animal que vinha para devastar e destruir. E, segundo a analogia do pensamento mágico-mítico, o perigo poderia ser desviado se, como acontece na epopéia de Gilgamesh, este fosse morto. $O$ culto do touro simbolizaria, pois, a vitória sobre uma remota catástrofe causadora de pavor entre os homens (Idem, p. 61).

\section{E, por fim, chegamos da trajetória...}

Com a conclusão de que estão no paradoxo medo versus adoração as raízes da manifestação folclórica conhecida, em nosso meio e tempo, como boibumbá. Há, pelo menos, certa analogia no encerramento tradicional da "brincadeira", quando se mata o boi e distribuem-se sua carne e vísceras. Apesar do simbolismo da morte - ou talvez por causa dele -, o amor da comunidade permanece e o "novo deus" renasce no ano seguinte. É uma forma de divinização contemporânea, que se realiza no plano social e não mais no existencial. De qualquer modo, a prática do "culto" ameniza as sufocações do cotidiano. Daí crermos que focalizar tal ação, forma reduzida das primitivas atitudes míticas, ganhou consubstância no contexto social em que estamos ora inseridos.

\section{Referências bibliográficas}

BARTHES, Roland (1989). Mitologias. $8^{\mathrm{a}}$ ed. Trad. Rita Buongermino e Pedro de Souza. Rio de Janeiro: Bertrand Brasil.

BRAVO, Nicole Fernandez (1998). Duplo. In: BRUNEL, Pierre. (Org.). Dicionário dos mitos literários. $2^{\mathrm{a}}$ ed. Trad. Carlos Sussekind. Rio de Janeiro: José Olympio; Brasília: Universidade de Brasília, p. 261-88.

CAMPBELL, Joseph (1995). O poder do mito. $12^{\mathrm{a}}$ ed. São Paulo: Palas.

CASSIRER, Ernest (1972). Linguagem e mito. Trad. J. Guinsburg e Miriam Schnaiderman. São Paulo: Perspectiva (Debates, 50). 
CHEVALIER, Jean \& GHEERBRANT, Alain (1995). Dicionário de símbolos; mitos, sonhos, costumes, gestos, formas, figuras, cores, números. 9a ed. Trad. Vera da Costa e Silva. Rio de Janeiro: José Olympio.

CIRLOT, Juan-Eduardo (1984). Dicionário de símbolos. Trad. Rubens Eduardo Ferreira Frias. São Paulo: Moraes.

COMMELIN, P. (1983). Nova mitologia grega e romana. Trad. Thomaz Lopes. Belo Horizonte: Itatiaia (Descoberta do Mundo, 28).

ELIADE, Mircea (1991). Imagens e símbolos; ensaios sobre o simbolismo mágico-religioso. Trad. Sonia Cristina Tamer. São Paulo: Martins Fontes. . (1994). Mito e realidade. $4^{\mathrm{a}}$ ed. Trad. Pola Civelli. São Paulo: Perspectiva (Debates, 52).

- (1992). O sagrado e o profano; a essência das religiões. Trad. Rogério Fernandes. São Paulo: Martins Fontes.

GUIMARÃES, Ruth (1995). Dicionário da mitologia grega. São Paulo: Cultrix.

JABOUILLE, Victor (1986). Iniciação à ciência dos mitos. Lisboa: Inquérito (Cadernos culturais, 120).

KERÉNYI, Karl (1994). Os deuses gregos. Trad. Octavio Mendes Cajado. São Paulo: Cultrix.

LOIBL, Elisabeth (1992). Deuses animais. São Paulo: Círculo do Livro.

PIRES, Orlando (1985). Manual de teoria e técnica literária. 2a ed. rev. amp. Rio de Janeiro: Presença (Linguagem, 15).

SHORTER, Alan W. (1993). Os deuses egípcios. Trad. Hugo Mader. São Paulo: Cultrix.

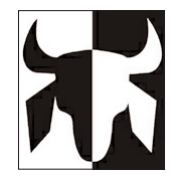

